SHS Web of Conferences 7, 02012 (2014)

DOI: $10.1051 /$ shsconf / 20140702012

(C) Owned by the authors, published by EDP Sciences, 2014

\title{
Investigation of Health Conditions and Advice on Physical Exercise for College Students--Taking Hebei Province as an example
}

\author{
Wang Guokun \\ Chengde Petroleum College, 067000 Chengde Hebei, China
}

\begin{abstract}
As the colleges and universities are considered as the cradles for development of high-level talents, the physical fitness of college students is decisive to the future construction and development of our country. Meanwhile, the college physical education, as an important component in school education, undertakes the important responsibility of improving and enhancing the constitution and health level of college students. Taking Hebei Province as an example, this article investigates part of constitution data of college student, and makes vertical and horizontal analysis on situations of engagement in physical exercise for college students, by which it can be concluded that: Most of the students in college have had necessary physical exercise within teaching hours according to course arrangement, but some of them expect to simply take the credits and pass the exam; It is advised that the management intensity of constitution and health level for students shall be enhanced, and the sound long-effect mechanism of constitution monitoring shall also be established.
\end{abstract}

Keywords. constitutional health; constitution investigation; physical exercise; physical education

\section{Introduction}

The National Education Reform and Development of Long-Term Planning Programs (hereinafter referred to as Educational Planning Programs) approved by State Council in May 2010 indicates that: "Education is a footing stone for vigorous development of nations and progress of society, and is also the fundamental route for comprehensive development of civil quality and our populations. The first step of making our country more powerful is to strengthen the education. The key factor for China's future development and Chinese great revival is talent, and the basis is education [1]."That is to say, the competition of comprehensive national strength in the new period is essentially the rivalry for talents, their qualities and physical conditions. It is significant to master the quality conditions of college students, find out the problems in current education, integrate Educational Planning Programs according to current situations, understand and improve the current constitution of college students, and deepen the new round of physical education innovation.

As an important part of school education, the college physical education undertakes the heavy responsibility of improving and enhancing the constitutional health level of students. As the top universities in Hebei Province, Hebei XX University, Hebei XX Normal University, etc. are the cradles for developing high-quality and high-tech talents. This article takes the constitutional health

This is an Open Access article distributed under the terms of the Creative Commons Attribution License 4.0, which permits unrestricted use, distribution, and reproduction in any medium, provided the original work is properly cited. 
conditions of students in four universities mentioned above as the research basis to conduct a test and investigation on large sample, which are of certain reliability, representativeness and research value. The analysis and research on the constitutional health conditions of this part of college students and exploration of strategies provide the decisions and basis for implementation of Education Planning Programs in our province in the new period and the reform of teaching system, for the purpose of providing reference of physical education innovation for other normal colleges and universities.

The variation of constitutional condition level and engagement in physical exercise for students known from the analysis and research in this article provide a certain reference for analysis and research work of college students' constitutional health in our province and country. It integrates the engagement of students in physical exercise to make a deep analysis on their constitutional health level, in which it identifies the problems in the engagement in physical exercise and their constitutional health, analyzes its influencing factors and proposes the corresponding strategies and suggestions.

\section{Relevant work}

Currently, many countries use the constitutional research to solve the health problems in nationals. In a very early stage, there were researches based on constitutional tests for students in America, Japan and New Zealand.

The literature[2] indicates that the constitutional research made by American constitutional experts can be generalized as: "The constitutional research has a long history in America, where the disciplinary development is also relatively comprehensive. In the early stage (before 1958), 7 indexes were selected for general investigation of national adolescents. Meanwhile, the corresponding research of exercise standard and test index was nationally launched. Then the test contents and indexes constantly went through reasoning, questioning and improvement. In 1988, a new Best Health Plan was published, and the finally selected test indexes included four aspects: cardiopulmonary function, muscular strength and endurance, flexibility, body composition, etc.."

It is indicated in the literature[3] that Japan really focuses on students' constitutional conditions: "In 2002, the test indexes were constantly improved on the original basis, with setting of general test indexes and limitation of age groups, then a new physical test standard was re-prepared, published and implemented: including two parts, one of which contains physical capacity related to development of athletic ability such as body composition, cardiorespiratory endurance, speed, muscular strength and endurance, explosive power, flexibility, dexterity, balance, etc.; and the other of which contains physical capacity related to health such as body composition, cardiorespiratory endurance, muscular strength and endurance, flexibility, etc.." The literature[4] indicates that in New Zealand, "some had used the famous muscular test method of Klaus Webb to test the students in the beginning, but every effort didn't finally succeed due to various reasons. By continuous exploration, the New Zealand Fitness Test (for the age from 6 to 15) was published in 1989, and the assessment indexes included four aspects, namely body composition, cardiopulmonary function, abdomen muscular strength and endurance and flexibility.

As is discovered from the constitutional research and analysis in America, Japan, New Zealand and other countries, most of the indexes of test contents, compared to our country, are related to body shape, cardiopulmonary functions, body quality, etc.. The index system of constitutional test contents for our students is relatively comprehensive, except for some part of test indexes that are different from those in other countries.

From the pilot test of Constitutional Health Standard for students in 2002 to the publishment of National Constitutional Health Standard in 2007, and then to the fourth Winter Long-distance Race Activity of Sunshine Physical Education organized and launched by our country in college campus, the constitutional health has become the hot spot of research this year. Some part of research in the literature[5-11] questions the test items of each reflection index in Standard; There are also some researches proposing new ideas for weight coefficient of each index of reflected body shape, body capacity and body quality; Some part of the research proposes supplement for the reflected body 
quality covered in the test indexes, and suggests to add test items of psychological quality reflection index and adaptation capacity index

\section{Research method and investigation data}

According to the notice and requirements of National Constitutional Health Investigation and Implementation Plan for Students, Hebei XX University and Hebei XX Normal University are determined as the monitoring sites. This article selects some part of students in those two universities as the research objects, and utilizes the combined methods of group sampling and random sampling to select the investigation samples required by the research.

This research process will conduct site test, issue questionnaires for students and talk to them to learn about their engagement in physical exercise; Then it will arrange the test data and questionnaires and conduct mathematical statistics for them; Thereafter, it will integrate the literature and questionnaires to conduct comparative, logic and other analysis method or step to research.

\subsection{Source of sample}

Select 1200 samples in the effective questionnaires as the research objects, and select the proportional relation of M-F ratio and the total number of students in each stage of four grades in universities which is basically kept equal. The selected number of samples is shown in Table 1.

Table 1. Number of selected samples in investigation questionnaires

\begin{tabular}{cccc}
\hline Grade & Male & Female & Subtotal \\
\hline $2009^{\text {th }}$ grade & 150 & 145 & 295 \\
$2010^{\text {th }}$ grade & 165 & 130 & 295 \\
$2011^{\text {th }}$ grade & 165 & 140 & 305 \\
$2012^{\text {th }}$ grade & 155 & 150 & 305 \\
Total & 635 & 565 & 1200 \\
\hline
\end{tabular}

According to the samples in Table 1, we make an analysis on the test result of freshmen participating in the test, expecting to conduct a further analysis on the physical exercise of senior high school students to find out their constitutional problems, and to propose certain requirements about the future life and physical education in colleges and universities. Table 2 provides statistics of total physical test result for samples of $10^{\text {th }}$ and $9^{\text {th }}$ grade students when they started to be admitted, and the physical test result for students of every age.

Table 2. Statistics of physical test result for samples (percent)

(a) Entrance result

\begin{tabular}{ccccc}
\hline Number of samples & Excellent & Good & Qualified & Unqualified \\
\hline $305(2011)$ & 8.9 & 51.7 & 38.1 & 1.3 \\
$305(2012)$ & 9.5 & 53.4 & 35.5 & 1.6 \\
\hline
\end{tabular}


(b) Current result

\begin{tabular}{ccccc}
\hline Number of samples & Excellent & Good & Qualified & Unqualified \\
\hline $295(2009)$ & 9.8 & 54.1 & 34.5 & 1.7 \\
$295(2010)$ & 10.1 & 57.6 & 31.3 & 1.0 \\
$305(2011)$ & 10.3 & 58.0 & 31.5 & 0.3 \\
$305(2012)$ & 9.5 & 53.4 & 35.4 & 1.6 \\
\hline
\end{tabular}

As shown in Table 2, most of the constitutional conditions lie in the level range of Good and Qualified $\left(89.8 \%\right.$ for $2011^{\text {st }}$ grade and $88.9 \%$ for $2012^{\text {nd }}$ grade) for students starting to step into universities, and only a small part lies in the level range of Excellent and Unqualified (10.2\% for $2011^{\text {th }}$ grade and $11.1 \%$ for $2012^{\text {th }}$ grade). The total result can reflect that most of the college freshmen are sub-healthy, which is basically consistent to national constitutional health situation for students. Meanwhile, the excellent rate of less than $10 \%$ and unqualified rate of about $1.5 \%$ become the main problem of physical education those two universities will face in the future; the result of most of the students is Excellent and Good, and the cumulative rates are all above $60 \%\left(60.6 \%\right.$ for $2009^{\text {th }}$ grade and $62.9 \%$ for $2010^{\text {th }}$ grade), which indicates that the overall constitutional health level for student pool in those two universities tend to be in a steady state.

According to the analysis of engagement in physical exercise for students when they have a PE lesson and are in their after-school time, the physical education is an obligatory lesson for freshmen and sophomores, and their constitutional conditions are to some extent improved even though they just simply want a pass in the test. The physical education is an optional lesson for juniors and seniors, and some students will be facing with pressures of obtaining certificates, graduate degree, employment, etc., for which they will spend less time on exercise and thus lead to a certain decrease of their results.

\subsection{Sample analysis}

According to the basic information of students, it is found that the college students commonly have some bad living habits and don't have good habit of physical exercise. We make an analysis on the physical exercise according to extracurricular physical activities and physical exercise for college students, expecting to find out the existent problem, and provide basis for improvement of students' constitutional health and promotion of course innovation of college physical education.

Table 3. Statistics of physical exercise time

\begin{tabular}{ccccc}
\hline Time & Number of male & Percentage & Number of female & Percentage \\
\hline Below 30min & 23 & 1.92 & 67 & 5.58 \\
30-45min & 102 & 8.5 & 153 & 12.75 \\
45-60min & 130 & 10.83 & 95 & 7.92 \\
Above 60min & 318 & 26.5 & 114 & 9.5 \\
Unstable & 95 & 7.92 & 103 & 8.58 \\
\hline
\end{tabular}

According to the time of engagement in exercise shown in Table 3,7.5\% of the students spend more than 30 minutes in exercise, $21.25 \%$ of them spend $30-45$ minutes, $18.75 \%$ spend $45-60$ minutes, $36 \%$ can ensure the engagement of above 60 minutes and $16.5 \%$ belong to the Unstable type. There are less than $40 \%$ of students that can ensure 1 hour spent in daily exercise, most of which are male, 
and the exercise time for female students is generally about 45 minutes. There is an obvious difference of exercise time between male and female students.

Overall, most of the students that engage in physical activities cannot ensure sufficient frequency and time, thus are difficult to achieve desirable effect of exercise, which shows a big difference from the physical requirements the education department makes for college students and the requirements of National Constitutional Health Standard for Students; The previous analysis finds that there's a huge difference between the study and living habits of students, and the instability of time and frequency to engage in activities may have close relation to that difference.

Table 4. Investigation of physical education items (multi-choice)

\begin{tabular}{lcccccc}
\hline & \multicolumn{3}{c}{ Male } & \multicolumn{3}{c}{ Female } \\
\cline { 2 - 7 } Jogging & Number & Percentage & Rank & Number & Percentage & Rank \\
Football/Basketball & 195 & 30.56 & 4 & 263 & 46.80 & 3 \\
Volleyball/Ping Pong & 496 & 77.74 & 1 & 101 & 17.97 & 6 \\
Badminton/Tennis & 243 & 38.08 & 3 & 196 & 34.88 & 4 \\
Aerobics/Yoga & 308 & 48.28 & 2 & 326 & 58.01 & 2 \\
Martial Arts/ & 112 & 17.55 & 7 & 342 & 60.85 & 1 \\
Shadowboxing & 135 & 21.26 & 6 & 95 & 16.90 & 7 \\
Swimming & 143 & 22.41 & 5 & 153 & 27.22 & 5 \\
Others & 109 & 17.08 & 8 & 90 & 16.01 & 8 \\
\hline
\end{tabular}

According to the investigation of physical education items that the students engage in, as shown in Table 4, the items which college students like will be varied from person to person, and there's a difference between male and female students. The items ranking the fourth and that the male students engage in include (as shown in Table 12): basketball and football which account for $77.74 \%$, tennis and badminton which account for $48.28 \%$, volleyball and Ping Pong which account for $38.08 \%$ and jogging which accounts for $30.56 \%$; For female students, the aerobatics and Yoga account for $60.85 \%$, with badminton and tennis for $58.01 \%$, jogging for $46.80 \%$, volleyball and Ping Pong for $34.88 \%$. Overall, most of the students choose jogging, three big balls and three little balls, and relatively less students choose swimming, martial arts, gymnastics and other items. There's a certain difference in the items selected by male and female students. The female students tend to choose the relaxed and entertaining items such as aerobatics, badminton and jogging, while the male students tend to choose the intense and competitive items such as basketball, volleyball, football and badminton.

Table 5. Motive to engage in exercise (multi-choice)

\begin{tabular}{ccccc}
\hline Motive & Male & Female & Total / Ratio (\%) & Rank \\
\hline Entertainment & 305 & 86 & $391 / 32.58$ & 1 \\
Constitution Improvement & 239 & 99 & $338 / 28.17$ & 2 \\
Body Building & 69 & 156 & $225 / 18.75$ & 4 \\
Making Friends & 97 & 85 & $182 / 5.08$ & 5 \\
Volition Exercise & 39 & 22 & $61 / 124$ & 8 \\
Lifetime Benefit & 87 & 37 & $124 / 10.33$ & 6 \\
Emotion Adjustment & 25 & 50 & $75 / 6.25$ & 7 \\
Exam Pass & 123 & 149 & $272 / 22.66$ & 3 \\
Performance of Physical Skills & 39 & 0 & $39 / 3.25$ & 9 \\
\hline
\end{tabular}


The exercise motive[12] mentioned in Table 5 refers to "the basis for college students to engage in physical activities, and meanwhile the need to exercise for students is the objective requirements of society and education towards the exercise of college students. It is often presented as the form of willingness, interest, etc. of exercise for college students, and plays a promotive role in exercise."

According to the investigation of diversified physical exercise motive for college students, as shown in Table 5, the Entertainment (32.58\%) ranks the first in the physical exercise motive, which is followed by Constitution Improvement $(28.17 \%)$, Exam Pass and Body Building. Some of them engage in the physical activities out of Making Friends. There's a huge difference of the exercise motive between male and female students. The male students tend to exercise for Entertainment, Constitution Improvement and Body Building, and the other part tends to exercise for Performance of Physical Skills; For female students, they mainly tend to exercise for Exam Pass and Constitution Improvement. The diversity of engagement in exercise for college students can indicate the demand and dream of pursuit of happy and healthy physical education for current college students.

\section{Strategic research and advice}

According to the analysis of students' constitutional health conditions, it is found that the constitutional health level of college students in our province is to some extent increased overall. However, there are some problems that shall be paid attention to, and we shall take effective measures to improve and enhance the constitutional health conditions for students.

According to the research, it is found that most of the students are for Exam Pass, but few of them know the purpose of the national constitutional investigation and annually conducted constitutional test in school. The students can better improve and develop the interest to engage in exercise only if they have a deep understanding of constitutional test. And the PE teachers can better organize and implement the test work only if they have a better understanding of test process and standard. The use of combined assessment methods of qualitative and quantitative assessment in physical education for students can tentatively implement the objective assessment of semester results for students based on the combination of constitutional test results and the students' physical education results.

Meanwhile, as the basis of lifelong physical education, the physical education in school shall take the responsibility to develop the solid awareness of lifelong physical education for students. The PE teaching of school shall organize rich and colorful physical activities, conduct publicity and education in multiple routes and levels, guide the college students to engage in physical exercise, make them understand the value and meaning of engagement in physical exercise, develop their interest of engagement in physical exercise, intensify their self-consciousness and initiatives of engagement in physical exercise, and gradually help the students establish a solid idea of lifelong physical education.

Furthermore, the teacher plays a leading role in teaching, and the school shall focus on improving the continuing education of PE teachers, improve the overall comprehensive qualities of professional skills, and lay a solid foundation for college physical education innovation in the new trend. The colleges and universities shall well implement the course innovation, teach students in accordance with their aptitude, treat them variedly from person to person, conduct centralized teaching respectively for students with different constitution and with relatively bad physical skills, implement purposeful, hierarchical and characteristic teaching and tutoring, for the purpose of creating a platform that they can perform their own skills, fully improving the physical education quality and enhance the pragmaticality of teaching.

In all, the formation of good lifelong physical education awareness to engage in exercise for students shall need the society and school to create a good atmosphere of physical exercise, solidate and improve their ideology and thus to establish a correct health conception. Meanwhile the school shall improve the teaching and physical exercise environment and increase the investment in large stadium, equipment and facility to provide more students with opportunities to engage in physical activities, thus to create conditions for improvement of students' constitutional health conditions. 


\section{Conclusion}

This article uses methods of literature, interview, comparative analysis, questionnaire, test and other research methods to conduct horizontal and vertical analysis on part of data and the engagement in physical exercise for students involved in the 2010 constitutional investigation in our province, and it concludes that:

It is found from the investigation in this article about the engagement in physical education for students, most of the students in college have had necessary physical exercise within teaching hours according to course arrangement, but some of them expect to simply take the credits and pass the exam; Through learning the physical education course, some students develop the habit of physical exercise, and can actively do proper physical exercise in after-school time. However, due to the limitation of space, facility, consumption, etc., the rate of engagement in physical exercise is far lower than the national standard.

Meanwhile, it is found from the analysis on constitutional health conditions for admitted students, they could not effectively do physical exercise due to academic pressure, heavy schoolworks, etc. in their senior high school period, and some of their test indexes were far lower than the national student standard. After entering universities, the students had a strong ability to accept new things, and meanwhile they do physical exercise under the constraint of educational course in school, thus their index results started to increase. However, with the cancellation of obligatory physical course and the incoming pressures of obtaining graduate degree and employment, the engagement of students in exercise started to decline, which led to reduction of constitutional health level for students. According to the dynamic analysis on the two test indexes of students in 2005 and 2010, it is found that with the issue of corresponding national policies, the school increased the concentration level, and the overall level of students had a certain rise, but the effect is not that obvious.

\section{References}

1. Research Task Group of Constitution and Health for Students. Interpretation of Constitutional Health Standard (Pilot Scheme) for Students[M].Beijing: People's Education Press, 2002. 8.

2. Research Group of Constitution and Health for Chinese Students.Investigation Report of Constitution and Health for Chinese Students in 2005[M]. Beijing: Higher Education Press, 2007.

3. Jiang Zhiming,Wu Hao. Comparative Research on Test Standard of Constitution and Health for Students in Middle F1 College [J]. Journal of Shanghai Institute of Physical Education, 2003.11:111-113.

4. Fu Jiliang. Comparative Analysis of Test Standard of Constitutional Health for Students in China and New Zealand [J].Journal of Chengdu Sport University,2005(4):102-104.

5. Li Wei.Analysis and Strategy of Test Data of Constitutional Health for College Students [J].Journal of Dezhou University, 2008.4:89-92.

6. Yao Xiaomin, Yu Ling, etc..Research on Current State and Strategy of Constitutional Health for Students in Middle and Southern University[J].Journal of Hunan Medical University (Social Science Edition),2009.5:164-165.

7. Yin Maiman, Zhang Fanrong, Yu Zhuxian. Perfection Research of Constitutional Health Test Items for College Students [J]. Journal of Shenyang Sport University,2006.6:76-77.

8. Xiao Xijun, Wang Dongdong. Empirical Research of Assessment Index System of Constitutional Health for College Students [J]. Journal of Shandong Sports Institute, 2010.10:66-69.

9. Cai Zhongjian, Yuan Jianguo. Analysis on Weight Coefficient and Correlation of Constitutional Health Index for College Students [J].Journal of Shanghai Institute of Physical Education, 2009.3:74-78.

10. Li Jianping. Development of Constitutional Health Assessment for Students in Our Country[J]. Journal of Physical Education, 2008.12:75-80. 
11. Zhen Zhiping,Zhang Yingqiu,Xing Wenhua. Research on the Evolution and Development of Constitutional Test Index System for Chinese Students[J]. Journal of Beijing University of Physical Education, 2006.7:928-927.

12. Ma Ning. Second Review of Status of Extracurricular Physical Exercise in Physical Education in School[J]. Journal of Physical Education, 2006,13(10):138-140. 